\title{
SPINOZA: O CONATUS E A LIBERDADE HUMANA
}

=

André Paes Leme*

Resumo: Este artigo tem por objetivo compreender o papel representado pelo conceito de conatus na filosofia de Baruch de Spinoza. Partindo da leitura da da Ética III buscaremos reconstruir a teoria da afetividade postulada pelo filósofo para demonstrar como a noção de conatus opera ao mesmo tempo como perseveração na existência e afirmação do desejo. O passo posterior será projetar uma unidade entre o existir e o desejar como a base para o correto entendimento da concepção de liberdade desenvolvida por Spinoza na parte V de sua Ética.

Palavras-chave: Spinoza, Conatus, Liberdade, Desejo, Ética.

O desejo é a essência da realidade (Jacques Lacan)

\section{I - Introdução}

O intuito deste trabalho é analisar a centralidade do conceito de conatus no projeto ético de Spinoza e o modo como esse conceito vai orientar sua teoria da afetividade. ${ }^{1}$ Para isso, exporemos um plano geral dessa teoria dos afetos, atentando ao momento em que surge nela a necessidade de um operador dinâmico, capaz de fundamentar sua efetividade. Mostraremos como, para Spinoza, apenas o conceito de conatus pode suprir a necessidade de tal operador. A fim de compreendermos a gênese de tal conceito, seremos obrigados a retomar seus pressupostos ontológicos nos livos I e II da Ética.

* Graduação USP 
Notaremos que Spinoza identifica o conatus com a essência mesma do homem, mas também com o esforço por ele empreendido para perseverar e expandir sua potência de existir. Buscaremos, então, mostrar como o conatus representa, para o holandês, ao mesmo tempo, um princípio de conservação e de afirmação da potência do homem. Feito isso, analisaremos como Spinoza se serve da idéia de conatus para operar a completa naturalização da vida afetiva e, com isso, promover a desvalorização da moralidade normativa e transcendente da tradição. Por fim, observaremos as implicações de tal conceito como critério imanente de uma clínica dos afetos ${ }^{2}$ que visa a afirmação plena e viva da liberdade humana.

\section{II - Por uma ciência da Afetividade}

Começamos, assim, por um sobrevôo seletivo sobre o livro III da Ética que busca ressaltar sua relevância no edifício ético spinozano e detectar o ponto de emergência do conceito de conatus no interior da dissecação da vida afetiva realizada pelo filósofo. Para Spinoza, o campo da afetividade constitui uma dimensão específica dos procedimentos mentais. Se, na parte II de sua Ética, ele se encarregara de enunciar as leis objetivas, no plano mais especificamente cognitivo, de tais procedimentos, isso não significa que sua filosofia não reconheça também a existência de uma lógica da afetividade por trás da aparente desordem da vida afetiva. Para o filósofo, e nisso consiste talvez sua grande novidade, a vida afetiva não é "irracional” nem absurda, mas sim uma produção natural passível de conhecimento e exame racionais. Na parte III da Ética, ele se coloca a tarefa de elaborar uma teoria racional dos afetos (sentimentos) ${ }^{3}$, uma geometria da vida afetiva, requisito indispensável para a edificação de um projeto ético que vise a ação prática.
A especificidade da teoria spinozana dos afetos consiste precisamente no princípio central da consideração dos afetos, enquanto coisas naturais, como efeitos regulados e ordenados da potência da natureza e da possibilidade de fazer deles objeto de um estudo plenamente racional, isto é, desprovido de todo julgamento de valor a partir de uma normatividade moral. Outro ponto que deve ser destacado acerca da teoria spinozana exposta na Ética III é seu horizonte ético, que já se coloca para além da ilusão de exercer, pela via da razão, um poder absoluto sobre as paixões. Conhecer as causas e os mecanismos dos afetos, é dar-se os meios por assim dizer de os transformar, em parte, em coisas que nos tragam mais efeitos benéficos do que nocivos.

Vale ressaltar que Spinoza não utiliza o termo afecção como um correlato de "afeto", termo, aliás, bastante raro no léxico filosófico da época e que poderia ser apreendido no sentido mais usual que designa a expressão "sentimento". Com efeito, ainda que a tradição tenha aproximado a afecção (affectio) daquilo que se dá no corpo e o afeto (affectus) de seu desdobrarse na alma, para Spinoza essa ainda não é a verdadeira distinção entre ambos. Para ele, as afecções referem-se aos acontecimentos que ocorrem aos modos finitos e aos efeitos nele gerados pela ação de outros modos. Já os afetos (affectus) correspondem: “à passagem de um estado a outro, tendo em conta a variação correlativa dos corpos afetantes" (Deleuze 5, p. 50). Quando o modo finito é afetado por outro modo exterior a ele, a modificação nele causada pode transcorrer como um aumento ou uma diminuição do grau de perfeição em que se encontrava anteriormente. Por isso, Deleuze afirma que se denominam afetos a intensidade da passagem de um estado a outro do modo afetado. Em outras palavras, o afeto é o signo de como o modo afetado se modifica através de uma afecção causada por outro modo, do aumento ou da diminuição de seu grau de perfeição anterior à afecção. Assim, pode Deleuze dizer: "Estas 
durações ou variações contínuas de perfeição denominam-se 'afetos' ou sentimentos" (Deleuze 5, p.50). Na definição III da Ética III, Spinoza afirma: "Por afeto compreendo as afecções do corpo, pelas quais sua potência de agir é aumentada ou diminuída, estimulada ou refreada, e, ao mesmo tempo, as idéias dessas afecções". Ele quer dizer que, ao contrário das afecções, os afetos não podem ser representados. Podemos apenas intuí-los como a variação da potência de agir (conatus) entre dois estados, antes e depois de uma afecção sofrida pelo modo finito. A questão parece complexa, mas Deleuze a explicita de maneira muito clara e elegante: "se chamará de afeto todo modo de pensamento que não representa nada. $\mathrm{O}$ que isso quer dizer? Tomem ao acaso o que qualquer um chama de afeto ou sentimento, uma esperança por exemplo, uma angústia, um amor, isto não é representativo. Certamente há uma idéia da coisa amada, há uma idéia de algo que é esperado, mas a esperança enquanto tal ou o amor enquanto tal não representam nada, estritamente nada" (Deleuze 6, p.6).

Spinoza distinguirá também entre afetos e paixões. Ele afirmará a existência de afetos ativos e passivos. O modo finito tem afetos ativos, isto é, ela age quando, nos termos spinozanos, sua ação se determina internamente e não por causas exteriores. Por outro lado, o homem padece, quer dizer, ele tem paixões, quando incapaz de ser a causa adequada de suas ações, ele é determinado por causas exteriores a si. Assim, podemos concluir que todas as paixões são afetos, mas nem todos os afetos são paixões, pois, segundo Spinoza, há afetos que, como vimos, ao contrário das paixões, são ativos. Se há afetos que não são paixões, isto quer dizer, como nos afirma Macherey: “[...] que a afetividade não exerce fatalmente sobre nosso regime mental uma influência perturbadora, definitivamente estranha à sua função positiva de compreensão racional: em outras palavras, sensibilidade e inteligência, não são faculdades distintas, potencialmente em conflito, mas suas intervenções, que procedem de uma única fonte, a capacidade que possui a alma de produzir afecções puramente mentais que são idéias (...), podem ser harmonizadas" (Macherey 8, p.18)

É exatamente neste ponto que uma teoria da afetividade encontra sua questão e seu âmbito éticos: como reduzir a quantidade de afetos passivos proporcionalmente ao incremento do número de afetos ativos? Cremos que o livro III da Ética aponta apenas para a possibilidade e para os operadores dessa ciência da afetividade. ${ }^{4}$ De modo que a questão acima colocada só pode ser plenamente respondida através do conceito de Beatitude e da transformação do próprio conhecimento em um afeto ativo, o que ocorre apenas na parte $\mathrm{V}$, que não abordaremos sistematicamente.

Mas podemos notar aqui que a via adotada pelo filósofo no Livro III da Ética apostará em um esforço de separação e classificação dos afetos por meio de um estudo da gênese da vida afetiva. Para classificar os afetos, Spinoza precisará estabelecer um critério de classificação. Caso contrário, como saberemos quais afetos nos fazem ativos e quais nos tornam passivos, quais devem ser promovidos e quais devem ser evitados? A resposta a essa questão é o conceito de conatus. Grosso modo, o filósofo adotará este conceito como um critério de avaliação imanente da vida afetiva. De modo que, de acordo com um conhecimento adequado da natureza humana, será positivo aquilo que fortalece o conatus, a potência de agir do homem e negativo aquilo que rebaixa seu grau atual de perfeição.

Spinoza define o conceito de diversas maneiras no interior da Ética, mas daremos especial atenção para a que surge nas proposições 6 e 7 da Ética III. Não nos prenderemos, no entanto, ao esgotamento dessas proposições, mas as utilizaremos, isto sim, conforme se impuserem as dificuldades naturais de exposição do conceito. Tentaremos demonstrar como o conatus se constitui em um princípio dinâmico que é a própria essência do homem. ${ }^{5}$ Ora como conservação de sua natureza, ora como pura afirmação e expansão de sua potência, isto é, aumento de seu grau de 
perfeição. Acreditamos que isso se deva à indissociabilidade, no interior da Ética, ao menos no que tange aos modos finitos da substância, entre sua essência singular e a ação de perseveração nessa essência. Notada a forma como o conceito de conatus se encontra no fundamento da teoria spinozana da afetividade, passemos no próximo tópico a exposição deste conceito.

\section{III - Conatus e Natureza Humana}

"Há uma só substância que possui uma infinidade de atributos, Deus sive natura, sendo todas as 'criaturas' apenas modos destes atributos ou modificações desta substância” (Deleuze 5, p.25). Para compreendermos o porque de Gilles Deleuze apontar esta como a principal tese do spinozismo, a concepção ontológica da existência de uma substância da qual, grosso modo, decorreria todo o existente, será necessário que analisemos o que Spinoza entende por substância. A contrapelo das afirmações do "celebérrimo" Descartes ${ }^{6}$ para quem o homem se caracteriza por um "composto substancial" entre alma e corpo, mas também de toda a tradição aristotélica, que considera substância "aquilo que existe por si mesmo", Spinoza demonstrará através das primeiras quinze proposições da Ética I os aspectos primordiais da substância: que ela é única, complexa, causa de si, pois de sua essência decorre necessariamente a existência, causa imanente de todas as coisas, pois é necessariamente infinita e consta de infinitos atributos, dos quais conhecemos apenas dois, isto é, o atributo pensamento e o atributo extensão.

"Deus, ou seja, uma substância que consta de infinitos atributos, cada um dos quais exprime uma essência eterna e infinita, existe necessariamente" (E I P11). O que nos interessa aqui é o fato de o filósofo reconhecer uma identificação entre Deus e seu conceito de substância. Isso nos autoriza a afirmar que se Deus é uma substância, consequentemente ele é causa de si, mas também de toda a infinidade de coisas existentes, pois o ato pelo qual o existente é por Ele produzido pode ser reduzido ao ato pelo qual Ele se autoproduz. Nisso consiste a idéia spinozana de causalidade imanente. A potência de Deus é sua própria essência, por isso conforme Delbos, Spinoza substitui a noção teológica de um Deus criador pela idéia racional de um Deus que, por assim dizer, produz suas "criaturas"7. O Deus sive natura, destacado por Deleuze como a tese central do filósofo da Ética, sustenta-se, portanto, pela constatação de que Deus é imanente à natureza, já que sua essência se exprime em tudo aquilo que nela existe.

Com efeito, sendo Deus a única substância ${ }^{8}$, toda a variedade do existente passa a ser considerada uma modificação desta substância. Isto autoriza Spinoza a afirmar, dando sequência a constituição de sua ontologia, na Ética II: "À essência do homem não pertence o ser da substância, ou seja a substância não constitui a forma do homem" (E II P10). Ora, se levarmos a sério a idéia de que tudo o que existe é, no limite, uma modificação da substância divina, a afirmação spinozana de que "a substância não constitui a forma do homem" pode até mesmo ser considerada supérflua. Resta saber, no entanto, a partir dessa ruptura de Spinoza com a tradição, claramente evidenciada pela proposição acima citada, o que vem a ser o homem. Para Chauí: "a causa de sua essência singular é a existência de outros homens que o produzem. A causa de sua essência é Deus: o homem é uma modificação (modus) dos atributos divinos, pensamento e extensão" (Chaui 2, p.16). De acordo com o que afirma Chaui, o homem é um modo finito da substância que se constitui a partir de duas modificações de dois dos infinitos atributos nela contidos: o atributo pensamento e o atributo extensão.

$\mathrm{O}$ atributo pensamento dará origem ao que conhecemos por alma e o atributo extensão ao que entendemos por corpo. No decorrer da Ética II, Spinoza desenvolve as concepções de corpo e alma e a relação existente entre eles. $\mathrm{O}$ holandês - bastante influenciado pelo princípio de inércia e, 
desse modo, pela causalidade eficiente interna e não mais pelo finalismo - define o indivíduo mediante o equilíbrio na proporção de relações de movimento e repouso entre as partes que constituem o corpo. Spinoza define o indivíduo pela causa eficiente, isto é, pela atuação de suas partes constituintes em uma mesma direção ${ }^{9}$. A ação do corpo passa a pautarse, então, pela garantia e manutenção dessa proporção de movimento e repouso que o constitui. Quanto à alma, o filósofo a definirá como idéia cujo objeto é o corpo ${ }^{10}$ e como consciência de si mesma. Podemos, assim, considerar a alma como a consciência das afecções que se dão no corpo. As relações estabelecidas entre corpo e alma se explicam pela famosa tese do paralelismo ${ }^{11}$ entre os atributos extensão e pensamento.

Como aponta Deleuze, a Ética estipula um ordenamento idêntico entre as idéias e os corpos, como duas séries diversas e autônomas, mas conectadas por um mesmo princípio e encadeamento ${ }^{12}$. O próprio Spinoza, a nosso ver, parece esclarecer esse ponto: “A ordem e a conexão das idéias é o mesmo que a ordem e a conexão das coisas" (E II P7). Para ele, como vimos, existe apenas uma substância exprimindo-se no homem por meio de duas modificações de dois dos infinitos atributos, isto é, o corpo e a alma. Como vimos, o corpo enquanto modificação do atributo extensão, é um indivíduo inserido na natureza e por ela afetado continuamente. Ao ser afetado, ele se comporta de forma passiva; quando afeta se comporta de forma ativa. Não podemos nos esquecer de que é do corpo e de sua relação de ser afetado e afetar os outros corpos que surgem as imagens denominadas por Espinosa como imaginação. Já a alma, enquanto expressão do atributo pensamento, é potência de pensar, capaz de ordenar as imagens das afecções do corpo, bem como produzir ideias por si mesma. A alma pode ser dita passiva se produz idéias a partir da imaginação e ativa se as produz a partir da sua própria potência.
Com efeito, a unidade do homem é formada pela modificação do atributo extensão e a idéia que representa, no atributo pensamento, esta modificação. De modo que não há relação de hierarquia entre tais modificações de ambos atributos, ou se quisermos, a alma não pode comandar o corpo nem o corpo pode determinar de qualquer forma a alma. Cada um deles é determinado pelo atributo do qual é modificação e a causalidade por eles seguida é determinada no interior de cada atributo. Isto significa que enquanto a alma se determina pelo atributo pensamento, o corpo é determinado pelo atributo extensão e não existe nenhuma relação de causalidade entre o intelectual e o corporal. $\mathrm{Na}$ fórmula de Chauí: "Alma e corpo exprimem no seu modo próprio o mesmo evento" (Chaui 2, p.16). Essa unidade complexa, formada através do paralelismo entre as séries de modificações do pensamento e da extensão, caracteriza uma potência imanente da substância, o que também podemos denominar, um conatus. ${ }^{13}$

O conceito de conatus é explicitado por Spinoza, como um princípio dinâmico balizado apenas pela causalidade eficiente, que determina as modificações dos atributos da substância, a partir da Ética III. Diz ele: “Cada coisa esforça-se, tanto quanto está em si, por perseverar no seu ser" (E III P6). Na proposição seguinte o filósofo denomina tal esforço de perseveração como a "essência atual” da coisa: "o esforço pelo qual cada coisa se esforça por perseverar em seu ser nada mais é do que sua essência atual" (E III P7). Essa "essência atual”, o conatus, que se constitui por meio da unidade entre a proporção interna de movimento e repouso do corpo e do encadeamento interno das idéias na alma, é o próprio ser do homem, aquilo que lhe garante que ele seja o que é, e não outra coisa. $\mathrm{O}$ esforço do homem para perseverar em sua existência, para transpor quaisquer obstáculos externos à sua afirmação, mas também para desenvolver-se e realizar-se o mais plenamente possível. Para Spinoza, 
não é possível conceber o indivíduo humano separado de seu esforço de perseveração em seu próprio ser, pois sua essência singular só existe enquanto atualização de tal esforço (conatus). Desse modo, podemos dizer que o corpo esforça-se "internamente" por assegurar a manutenção de seu equilíbrio interior, enquanto a alma opera a consciência deste esforço. Como cada conatus singular se vê continuamente em relação aos demais, a natureza e a exterioridade se revelam um complexo de causas que podem incrementar ou reduzir a efetividade do esforço de cada um em perseverar em sua existência, isto é, o seu conatus.

É nesse sentido que o Conatus é, como dissemos no início, um princípio dinâmico que funciona como fundamento para a teoria spinozana da afetividade, pois será a partir do efeito de aumento ou diminuição causado à potência de existir que o filósofo distingurá entre o agir e o padecer, ou se quisermos, entre os afetos ativos e os passivos (paixões). Quando se deixa tomar por todas as causas externas que visam o enfraquecimento de sua potência de agir, a diminuição de seu conatus, o indivíduo padece de uma paixão.

No entanto, se ele é capaz de aumentar sua potência de existir aproveitando-se dessas causas externas, isto significa que o indivíduo age ativamente. Podemos concluir que, quando afetado por paixões, o conatus é incapaz de impor sua potência sobre o que lhe é externo, enquanto que por meio da ação ele aumenta sua potência incorporando as causas exteriores e impondo-se sobre elas. Como nos diz o próprio filósofo: "Digo que agimos quando, em nós ou fora de nós, sucede algo de que somos a causa adequada, isto é (pela def. prec.), quando de nossa natureza se segue, em nós ou fora de nós, algo que pode ser compreendido clara e distintamente por ela só. Digo, ao contrário, que padecemos quando, em nós, sucede algo, ou quando de nossa natureza se segue algo de que não somos senão causa parcial" (E III D2). A partir disso Spinoza relaciona a ação à idéia de causa adequada e a paixão à de causa inadequada, pois a ação determina um aumento do conatus, enquanto a paixão implica em seu enfraquecimento. Como explica Chauí: "A partir de agora, o indivíduo singular passa a ser designado como causa: causa adequada (causa adaequata), se os efeitos que produzir puderem ser explicados apenas por sua própria natureza; causa inadequada (causa inadaequata), se os efeitos que produzir não puderem ser explicados apenas por sua natureza, mas pela interferência de causas externas ou potências alheias à sua" (Chaui 3, p.136). Assim, concebemos o conatus, a essência do indivíduo singular, como potência não apenas de existir, mas também de agir. Para o conatus, já não se trata apenas de manter o atual estado, conservar o equilíbrio nas relações de movimento e repouso (inércia) no corpo e de sua consciência na alma, mas também de uma atividade pela perseveração no ser ${ }^{14}$. Acrescenta-se à concepção "mecanicista" do conatus o esforço vital pela destruição dos impedimentos externos a tudo aquilo que possa expandir a potência de agir. À medida que no corpo o conatus atende pelos apetites, no que concerne à alma podemos identificá-lo com o desejo. Desse modo, o desejo é, na alma, a consciência dos apetites do corpo. No entanto, Spinoza não hesita em afirmar: "O desejo é a própria essência do homem, enquanto esta é concebida como determinada, em virtude de uma dada afecção qualquer de si própria, a agir de alguma maneira" (E III DA1).

O leitor atento rapidamente notaria que o filósofo parece hipostasiar o desejo como a definição mais precisa do esforço dinâmico que caracteriza o conatus, em detrimento dos apetites surgidos dos "mecanismos" corporais. No entanto, Spinoza esclarece, na explicação de tal definição, que prefere, para evitar o risco da tautologia, não reduzir o desejo aos apetites, mas sim "dar-lhe uma definição que abrangesse todos os valores, que abrangesse todos os esforços da natureza humana que designamos pelos nomes de apetite, vontade, desejo ou impulso (...) Compreendo aqui pelo nome de 
desejo todos os esforços, todos os impulsos, apetites e volições do homem, que variam de acordo com o seu variável estado e que, não raramente, são a tal ponto opostos entre si que o homem é arrastado para todos os lados e não sabe para onde se dirigir" (E III DA1 exp.).

Se o desejo pôde ser compreendido por Spinoza como a própria essência do homem, devemos entender seu funcionamento como uma espécie de motor-movente do conatus, sempre em busca daquilo que possa aumentar sua potência. Assim, seja como causa adequada ou inadequada, o desejo tem o poder de determinar afetivamente o indivíduo.

Ora, isso mostra que é da natureza do conatus exprimir-se por meio do desejo, da busca por objetos que sejam capazes de expandir sua potência e auxiliar em sua preservação. Mas, como vimos acima, o desejo pode se estabelecer ativamente quando aumenta a potência de existir, ou passivamente quando a diminui. Se determinado por causas exteriores a si, o desejo é passividade, inadequação. Mas, quando determinado por causas internas, a passividade deixa lugar à ação. O homem se torna causa adequada de si mesmo, pois cessa a distância entre o conatus e o objeto de seu desejo. Ao tornar-se causa adequada de si mesmo, o homem fortalece seu conatus, aumenta sua potência de existir e agir e reproduz, em escala modal, a imanência entre a causa e o causado no plano de atividade da substância.

O filósofo nos oferece com o modelo do conatus nada menos que uma concepção de eticidade totalmente renovada, pois a possibilidade de exercer domínio sobre as paixões já não passa mais pela normatividade valorativa da moral cristã, pela concepção do homem como um "Imperium in imperio" 15 capaz de submeter racionalmente os afetos através do império da razão. A concepção ética de Spinoza vislumbra, pelo contrário, a transformação da relação do homem com a afetividade, a reconciliação do homem com suas paixões, fazendo dele a causa adequada de sua vida afetiva para que ele possa determiná-la adequadamente ao invés de por meio dela padecer. Em outras palavras, Spinoza propõe uma Ética que se pauta pela busca do prazer (aumento de potência do conatus) e se encontra ciente da impossibilidade "ontológica" de eximir-se do plano das paixões, afinal, como vimos, o filósofo definiu o conatus, a essência atual do homem, como uma inclinação natural ao aumento de sua potência (desejo). A saída spinozana, reconhecendo a impossibilidade de superar a afetividade, realiza sua naturalização e oferece ao homem a possibilidade de controlar seus afetos tornando-se causa adequada deles.

Com efeito, podemos afirmar que o homem, por natureza, sempre buscará o que aumenta sua potência e afastará o que a diminui, isto, porém, não significa que os homens saibam verdadeiramente (conhecer é conhecer pela causa) o que aumenta ou diminui sua potência de existir, seu conatus. Não são poucos os que perseguem os objetos de seus desejos acreditando estarem em busca de um aumento de potência, quando, na verdade, só alcançam o enfraquecimento do conatus. Estes são vítimas da inadequação, diz Spinoza, das paixões, que apesar de completamente naturais, os escraviza totalmente. Por ser um modo finito da substância divina, o homem precisa, para existir e conservar-se, estabelecer relações causais com outros corpos. É desse modo que surgem as paixões, desse confronto originário com as causas exteriores. Como nos mostrou Spinoza, não podemos dizer que tal conflito se deva à busca por um objeto comum, no sentido de uma finalidade pela qual se estabeleceria uma disputa, pois o homem se determina pela sua causa eficiente, que é o conatus. Por isso dissemos antes que o conatus (expansão da potência) é o único critério da ação humana, o que invalida completamente uma moral normativa. É o homem, o conatus, que impõe valor às coisas, diz Spinoza, como que num jubiloso e intempestivo cântico da desvalorização de todos os valores. Conforme afirma o filósofo, é de nossa ignorância da causalidade eficiente 
que se alimenta a mistificação secular do finalismo ${ }^{16}$. Como ignoram as causas (eficientes) daquilo que desejam, os homens continuamente apontam para fora de si a finalidade de suas ações e pensam assim justicá-las. Desse modo, crendo-se livres e autônomos na afirmação de suas vontades, nada mais fazem do que condenar-se à passividade e à resignação.

\section{IV - Conclusão - O Conatus e a afirmação da liberdade}

Como vimos, a filosofia de Spinoza sucede de uma maneira geral de um esforço intelectual pelo reconhecimento da importância da afetividade para a realização plena da vida. Retomamos os pressuposto ontológicos do spinozismo para reconhecermos a centralidade do conceito de conatus nesse empreendimento e sua articulação com a ciência da afetividade. Definimos o conatus, juntos de Spinoza, como o esforço humano em perseverar na existência, isto é, a própria essência do modo finito, existente apenas enquanto reafirmação da potência de seu ser finito.

A partir daí demonstramos como o aumento da potência do conatus é o único parâmetro seguido pelos homens no balizamento de suas ações. Em seguida vimos que Spinoza define a determinação afetiva do desejo em termos de adequação e inadequação às suas causas. Assim, o filósofo pode dizer que a grande maioria dos homens padece justamente porque, ainda que ajam sempre buscando expandir sua potência, conforme manda sua natureza, eles são incapazes de perceber quais são as coisas realmente capazes de fortalecer essa potência, pois, possuem um conhecimento inadequado das causas do desejo. Por outro lado aqueles que possuem uma postura ativa, ou seja conhecem adequadamente as causas daquilo que desejam, serão capazes de realizar aquilo que o filósofo entende por uma vida de liberdade. Desse modo, resta-nos apenas compreender como se dá o conhecimento adequado das causas do desejo e auto-determinação do conatus par darmos por encerrada a tarefa que aqui nos propusemos.

Não pretendemos, contudo, esgotar as questões tratadas nos livros IV e V da Ética, mas apenas fazer alguns apontamentos sobre a relação entre o conceito de conatus e a afirmação da liberdade por meio do conhecimento adequado das causas do desejo. Inicialmente, podemos dizer que, para o filósofo holandês, valores-chave da moral cristã como bem e mal, definem-se apenas pelo aumento ou a diminuição da potência de agir. Com efeito, aquilo que aumenta a potência singular de cada homem é por ele considerado como um bem, já aquilo que diminui tal potência é tido como um mal. Assim, para Spinoza, bem e mal adquirem um caráter nominalista, para não dizer até mesmo relativo. Ele nega a tais conceitos sua qualidade transcendente, aquela que seria, na ação moral, imposta de fora, ou perseguida pelo homem de forma pretensamente livre. Ao fazer isso, a Ética naturaliza tais conceitos impossibilitando o julgamento moral transcendente da ação humana e a responsabilização do agente moral.

No spinozismo, saem de cena os valores transcendentes que pairavam sobre a consciência pecadora dos homens como a sombra aterrorizante de um Deus antropomórfico, e vêm à luz uma relação imanente de duração indefinida ${ }^{17}$ entre o homem e o mundo na qual a potência do conatus pode incrementar-se ou diminuir e até mesmo extinguir-se. A tábua das leis e o ressentimento moral são varridos do campo da ética para darem lugar ao conhecimento (pela causa) daquilo que nos envenena, ou fortalece. Conforme Deleuze: "A lei é sempre a instância transcendente que determina os valores bem-mal, mas o conhecimento é sempre a força imanente que determina a diferença qualitativa dos modos de existência bom-mau" (Deleuze 5, p.35). Àquilo que aumenta verdadeiramente a potência de existir e agir, que fortalece $o$ conatus, ou seja o desejo do qual o indivíduo é causa adequada, Spinoza denominará afetos alegres. $\mathrm{O}$ ato mesmo pelo qual o conatus alcança 
o aumento de potência, incrementa seu grau de perfeição, Spinoza reconhece como alegria. Já a tristeza ele distingue como o inverso, isto é, aquilo que diminui a potência do indivíduo.

O esforço ético da teoria spinozana da afetividade caracteriza-se como uma crítica mordaz das paixões tristes e como o único caminho, arrojado e prazenteiro, para uma afirmação afortunada da potência venturosa da vida. O vitalismo spinozano pode ser compreendido como uma espécie de prática clínica $^{18}$ dos afetos. Pois, já não contando mais com o universal valorativo-transcendente como guia prático da ação moral, a trilha para a realização da liberdade humana se revelará como um procedimento terapêutico, no qual a moderação do desejo através do conhecimento de suas causas faz do homem um ser ativo, capaz de determinar mais seus afetos, à medida que é por eles menos determinado.

A grande contribuição da Ética de Spinoza talvez consista na percepção de que o finalismo e sua moral levam o homem a uma vida de servidão, sempre em busca da satisfação de seus desejos por um fim exterior a si (o outro, Deus, a lei), quando, no limite, a liberdade consiste apenas no conhecimento interno e na realização daquilo que fortalece a potência humana de existir. A hipótese ética do spinozismo rompe definitivamente com a tradição ao deslocar a vida ética do solo tradicional do império racional sobre os afetos para uma espécie de cartografia dos desejos que permita ao homem orientar-se adequadamente neles. ${ }^{19} \mathrm{E}$ isso não significa guiar-se no limbo da vida afetiva pela luz natural da razão, pois, como demonstra o filósofo na Ética V, um afeto só pode ser determinado por outro mais potente.

Assim, orientar-se adequadamente significa fortalecer as paixões alegres, aquelas capazes de afirmar e expandir o conatus, em detrimento das tristes. Com efeito, apenas a intensidade de uma alegria pode afastar o homem do ressentimento, do ódio, da vingança e de todos os outros afetos que diminuem a sua potência. Orientar-se adequadamente, significa, portanto, fortalecer a virtude, que spinoza reconhece como afirmação da potência, tanto do corpo, por meio de sua capacidade de afetar positivamente outros corpos, como também da alma através de seu poder de conhecer adequadamente. Se o desejo, motor-movente do conatus, já não se impõe por uma causa exterior a si, a alma deixa de ser passiva e se torna ativa, o conhecimento é "sentido" como uma atividade; ele se torna, segundo a famosa fórmula, o mais potente dos afetos e o homem se revela causa adequada de si mesmo.

Desse modo, Spinoza conceberá como livre não aquele que, imaginando-se detentor de uma vontade autônoma (livre-arbítrio), não cessa de encontrar-se distante daquilo que deseja, pois é incapaz de conhecer as causas de seu desejo (e daquilo que é por ele desejado). Mas sim, aquele que consolida-se como a causa adequada de seus afetos, pois é capaz de romper a distância entre desejo e objeto e restituir, no interior do modo finito, o esquema da imanência entre a substância divina e aquilo de que ela é a causa adequada, isto é, tudo o que no mundo existe. É aí onde findam a servidão e o finalismo que começa, plena e esplendorosa, a afirmação da liberdade: Beatitudo.

\section{REFERÊNCIAS BIBLIOGRÁFICAS}

1. BOVE, L. La stratégie du conatus. Paris: J. VRIN, 1996

2. CHAUI, M. Vida e Obra. In: Espinosa. Coleção Os Pensadores. São Paulo: Nova Abril Cultural, 2004.

3.___. Política em Espinosa. São Paulo: Companhia das Letras, 2003.

4. DELBOS, V. Le Spinozisme. Paris: Société française d'imprimerie, 1916

5. DELEUZE, G. Espinosa: Filosofia Prática. Tradução D. Lins e F. P. Lins. São Paulo: Escuta, 2002.

6. _. Cursos de Gilles Deleuze ministrados em Vincennes. Tradução de Emanuel Angelo da Rocha Fragoso e Hélio Rebello Cardoso Jr. Edição virtual 
consultada em agosto de 2012: http://www.4shared.com/office/jWxoVn6z/ gd_spinoza_vincennes_port.html?cau2 $=403 \mathrm{t}$ Null.

8. MACHEREY, P. Introduction à l'Étique de Spinoza: troisième partie. Paris: PUF, 1997.

9. SÉVÉRAC, P. "Conhecimento e afetividade em Spinoza". In: O mais potente dos afetos: Spinoza e Nietzsche. São Paulo: Martins Fontes, 2009.

9. SPINOZA, B. Ética. Tradução de Thomaz Tadeu. Belo Horizonte: Autêntica, 2009.

\section{SPINOZA: THE CONATUS AND THE HUMAN FREEDOM}

Abstract: This article aims to understand the role played by the concept of conatus in the philosophy of Baruch Spinoza. From the reading of the Ethics III we'll seek to reconstruct the theory of affection postulated by the philosopher to show how the notion of conatus operates at the same time as perseveration in existence and affirmation of desire. The subsequent step will be to design a unity between existence and desire as the basis for a proper understanding of the concept of freedom developed by Spinoza in Part V of his Ethics.

Keywords: Spinoza, Conatus, Freedom, Desire, Ethics

\section{NOTAS}

1. Ética III. A origem e a natureza dos afetos. Cf. Spinoza 9, p. 95.

2. A psicanálise, enquanto uma mediação clínica da vida afetiva, encontra suas raízes também em Spinoza. Jacques Lacan nunca deixou de endossar tal interpretação e a citação em epígrafe em sua tese de doutorado (Da psicose paranóica em suas relações com a personalidade) é um trecho da Étca.

3. Sobre a noção de afeto em Spinoza, ver Deleuze 5, p.49

4. Acreditamos que no âmbito da integralidade do projeto ético spinozano a ciência dos afetos exerça um papel fundametal para o desenvolvimento de seu conceito de liberdade em rompimento com a noção tradicional de vontade. Para ele, a liberdade se dá em relação à essência e do que dela decorre. Cf. Spinoza 10, Ética V, Prefácio.

5. "Identificando essência e potência, a demonstração de que o conatus é a essência atual de um ser singular nos faz compreender que os apetites (no corpo) e as volições (na mente) são os aspectos atuais da potência de agir e existir, que por isso mesmo são causas eficientes determinadas por outras causas eficientes e não por fins." Cf. Chaui 3, p. 141.

6. Spinoza reconhece o empreendimento cartesiano, mas critica sua má-compreensão da natureza humana que o acabou levando a equívocos também no que concerne à visão sobre os afetos: "O muito celebrado Descartes, embora acreditasse que a alma tinha, sobre as suas ações, um poder absoluto, tentou, todavia, explicar os afetos humanos pelas suas causas primeiras e demonstrar, ao mesmo tempo, o caminho pelo qual a alma pode adquirir um império absoluto sobre os afetos. Mas, na minha opinião, ele nada demonstrou, a não ser a penetração do seu grande espírito". Cf. Spinoza 10, Prefácio da parte III.

7. Ver Delbos 4, p. 63.

8. Spinoza demonstra a impossibilidade da existência de mais uma substância com o mesmo atributo. Cf. Spinoza 10, Proposições 1 a 8 da primeira parte.

9. "Graças a ideia do indivíduo como integração e diferenciação interna dos constituintes e do princípio de aumento ou diminuição da potência ou intensidade da força pelas relações com as potências externas - os constituintes fracos submetendose às pressões externas; os constituintes fortes não só resistindo a elas, mas sobretudo vencendo-as -, Espinosa pode conceber o conflito com interno ao indivíduo, tanto quanto externo a ele." Cf. Chaui 3, p. 137.

10. Spinoza define a alma como ideia do corpo. Cf. Spinoza 10, prop. 13 da segunda parte.

11. Para uma revisão da questão de paralelismo, ver: C. Jaquet. L'union du corps et de l'esprit. Affects, actions et passions chez Spinoza. Paris: PUF, 2004.

12. Cf. Deleuze, 1981, pg. 74-75

13. "Entramos, agora, na região concreta na qual os indivíduos não se esforçam apenas para manter seu estado, mas para manter seu ser." Cf. Chaui 3, p. 135.

14. Tal passagem, para ser mais perfeita, deveria expor aquilo que Spinoza entende por "noções comuns" (cf. Spinoza 10, EII P37, 38, 39), no entanto, dado nosso interesse em trabalhar o conceito de conatus e sua relação com a liberdade, não será esta a ocasião para fazermos tal exposição de modo detido.

15. Cf. Essa fórmula aparece no prefácio da Ética III para representar a concepção tradicional do homem como senhor das forças da natureza externa e de sua própria.

16. Ver: Spinoza 10, Apêndice da primeira parte.

17. Spinoza demonstra a questão da duração indefinida de uma essência atual na prop. 8 da terceira parte da Ética. 
18. Ver nota 2.

19. "O homem é livre na exata medida em que tem o poder para existir e agir segundo as leis da natureza humana [...]. A liberdade não tira, mas põe a necessidade do agir." Cf. Spinoza, Tratado Político, cap II $§ 7$ e 11.

\section{BREVES CONSIDERAÇÕES SOBRE A METAFÍSICA DE LEIBNIZ}

Resumo: Neste texto, pretendemos fazer uma breve análise da metafísica leibniziana, tomando como fio condutor a noção de substância individual — que desembocará no conceito de mônada - , de sorte a tentar acentuar algumas de suas implicações e pressupostos. Passando pela criação e pelo sistema de determinação universal que ela acarreta, pretendemos mostrar de que maneira a substância é como que um espelho de todo o universo, a fim de mostrar sua relação com o restante das substâncias e, particularmente, explicitar aquilo que Leibniz denominará “corpo orgânico", tentando resolver o clássico problema da união da alma e do corpo.

Palavras-chave: metafísica, mônada, expressão, união substancial, corpo orgânico.

Poucas teses leibnizianas causaram tanto estranhamento - que o diga Arnauld! - quanto a enunciada no $§ 13$ do Discurso de Metafísica: "a noção duma substância individual encerra, duma vez por todas, tudo quanto the pode acontecer" (LEIBNIZ 8, p. 128). Para compreendê-la, todavia, devemos primeiramente precisar em que consiste a noção de uma substância individual. "É correto, diz Leibniz, quando se atribui grande número de predicados a um mesmo sujeito e este não é atribuído a nenhum outro, chamá-lo substância individual” (LEIBNIZ 8, p. 124). Mas tal definição, apenas nominal, não é suficiente para saber de que maneira o 